\title{
Delving into the Relationships among Iraqi EFL Learners' Willingness to Write, Personality Types and Writing Ability
}

\author{
English Department, Islamic Azad \\ University, Mashhad, Iran.

\section{*Corresponding Author: \\ ×afaravani@yahoo.com}

Ahmed Sharrad and Akram Faravani*

Received: 05 December, 2020

Accepted: 15 January, 2021

Published: 30 January, 2021

\begin{abstract}
It is highly conspicuous that learning and reaching high levels of mastery in writing and the psychological factors affecting it has an increasing importance. A common strategy that has attracted more attention in the field is the study of the possible effect of individual differences including willingness to write and personality type on the writing performance of language learners. As in particular no study in Iraq, to our knowledge, has considered such relationships, the present study dissects the links between EFL Iraqi learner's willingness to write, writing ability and personality types. To homogenize the learners, 200 English university students from Diwaneyah English language departments were selected through convenience sampling and were required to participated in Oxford Placement Test from which 120 EFL language were considered intermediate. The intermediate participants were also asked to fill out two questionnaires of Willingness to write and five-factor personality type and complete a writing task. The Pearson correlation between the scores showed that willingness to write and writing ability are moderately correlated and that from among five sub-factors of personality traits, conscientiousness has the highest positive correlation and Neuroticism has the lowest negative correlation with writing ability. The findings of this study have important implications for teachers and administrators to know how to consider psychological factors to improve students' writing ability.
\end{abstract}

Keywords: Five-Factor personality type, Individual differences, Personality type, Willingness to write, Writing ability

\section{Introduction}

Writing is now a mature field which is thoroughly known as being extremely complex, multidimensional, and complicated and is under the influence of many cognitive and affective factors [1]. It is highly conspicuous that learning and reaching high levels of mastery in writing has an increasing importance and a great number of researchers, consequently, tried to study this phenomenon in the field of teaching language skills. However, there exist many unsolved problems regarding the ways to promote students' writing ability. Among the important unsettled problems that confront us is the investigation of cognitive and affective factors influencing the writing ability. There are many alternative methods available for solving these problems, two of which is delving into the relationships between learners' willingness to write, personality types, and writing ability.

Historically, there has been a great deal of research findings and claims regarding the significance of cognitive and non-cognitive factors conducive to the enhancement of writing ability in the literature as it plays a fundamental role in language learning and communication. Moreover, writing is considered as the foundation of all communication and practice, especially in the educational settings where students need to express themselves in contexts related to their particular subjects; besides, writing has proved to be an essential skill in making direct communicative interaction where the learner has the opportunity to express himself [2]. Appertaining to the role of psychological factors, difference among language learners in how of learning is a logical phenomenon called individual differences [2-4]. Dornyei [5] regards 
differences among learners important since they cause some distinctions among them in the form of learning and language use. Some important different factors which show individual differences in learning a foreign language are different intelligence types, learning styles and language learning strategies [6-8].

One important individual difference which has proved influential in learning a foreign language is personality type which plays a vital role in the process of language learning especially writing $[4,9]$.

Throughout the recent past decades, many researchers have spent time searching and studying the role of personality type and the ways they can influence learning a foreign language and found a great number of dimensions of learner differences influencing the ways students learn a foreign languages, perform in a real language use situation, and finally achieve different levels of success [10].

We have undergone a rethinking of the issue by considering the role of personality type and willingness to write in writing ability since writing skill is an important communicative language skill. A glance back through the literature shows a direct correlation between different personality types and writing ability $[11,12]$. In other words, a person who is engaged in the act of writing is at the same time under the influence of his/her personality type [12]. Likewise, another important factor conducive to become a good writer is willingness to write since skilled writers with enough willingness to write can better encode meaning into printed text precisely and efficiently [13]. Willingness to write is regarded as a sub-component of willingness to communicate construct [14]. Despite the fact that personality types have been studied in relation to different language skills, there has been scarce studies delving into the relationships among intermediate EFL Iraqi students' willingness to write, personality types including openness, conscientiousness, neuroticism and agreeability and writing ability. For that reason, more specific research questions should be introduced and investigated in this field including:

Q1. Is there any significant relationship between Iraqi EFL learners' willingness to write and writing ability?

Q2. Is there any significant relationship between Iraqi EFL learners' personality type and writing ability?

- Q 2a. Is there any significant relationship between Iraqi EFL learners' openness to experience and writing ability?

- Q 2b. Is there any significant relationship between Iraqi EFL learners' agreeableness and writing ability?

- Q 2c. Is there any significant relationship between Iraqi EFL learners' extraversion and writing ability?

- Q 2d. Is there any significant relationship between Iraqi EFL learners' conscientiousness and writing ability?

- Q 2e. Is there any significant relationship between

Iraqi EFL learners' neuroticism and writing ability?

\section{Methods}

The methodology part deals with participants and setting and instrumentation.

\section{Participants and setting}

From 200 EFL learners who were selected through convenience sampling from Al- Qadisiyah University and Imam Al- Kadhim college, 120 (48 male and 72 female) EFL intermediate language learners were selected based on their scores in Cambridge Quick placement test 2004 (QPT). The participants' age ranged from 21 to 27 . In addition, they were ensured that all of the obtained information would be kept confidential and only used for the purpose of the present research.

\section{Instrumentation}

To collect the required data, the following instruments were used.

\section{Willingness to write questionnaire [14]}

To measure the participants' willingness to write, Khajavi et al. [14] WTW questionnaire was used. It is a 38- item questionnaire based on Likert scale ranging from definitely willing to definitely not willing. The internal reliability of this questionnaire was reported as 0.95. The estimated time to fill the questionnaire was 5 minutes.

\section{Khormaee's five-factor personality type [15]}

In order to determine the participants' personality type, Khormaee's five - factor personality type [15] was used. The questionnaire consists of 21 items with five domains of personality types including extraversion, agreeableness, openness, neuroticism, and conscientiousness, each of which has 4 items except extraversion which has 5 items. The reported internal reliability, according to Khormaee [15] were as follows: extraversion $(=.80)$, agreeableness $(=.79)$, openness $(=.87)$, conscientiousness $(=.72)$ and neuroticism (=.88). The needed time for the participants to fill the questionnaire was 20 minutes.

\section{Oxford quick placement test}

The Quick Placement Test (OQPT, 2001) with 60 items was used to estimate EFL level of proficiency. Based on participants' scores on such a test, they can be assigned to three proficiency level groups: low, intermediate and high. According to the instructional manual accompanying the test, the test takers whose scores are between 50 - 69 out of 100 are intermediate EFL learners and were selected as the participants of the study. 


\section{Writing test}

To measure the participants writing ability, a writing test titled as "What are the characteristics of a good teacher" was students. As the rating of the writing pretests might be rather subjective, and to ensure maximum reliability, two raters graded the compositions based on Wang and Liao's [16]' writing scoring criteria. The inter-rater reliability index obtained from Pearson correlation to determine consistency among raters was found to be 0.84 meaning that there was enough agreement between the two raters. Wang and Liao's [16] writing scoring rubric includes focus, elaboration/support, organization, conventions, and vocabulary as the criteria for scoring the written assignments. There are different writing scales from which Wang and Liao's [16] is selected due to its comprehensibility for the researcher.

\section{Results}

\section{Checking normality}

In order to run parametric tests, there are a number of assumptions to be met. To establish the essential assumptions of the data analysis, Kolmogorov-Smirnov was used to reveal the normality of distribution.

\section{Table 1}

The results of K-S Test.

\begin{tabular}{lcc}
\hline & df & Sig. \\
\hline Extraversion & 120 & .09 \\
Agreeableness & 120 & .19 \\
Conscientiousness & 120 & .12 \\
Neuroticism & 120 & .07 \\
Openness to experience & 120 & .12 \\
Willingness to write & 120 & .12 \\
Writing ability & 120 & .07 \\
\hline
\end{tabular}

As it can be seen, the obtained sig value for all variables is higher than .05. Therefore, it can safely be concluded that the data is normally distributed across all the variables.

\section{Descriptive statistics}

Table 2

Descriptive statistics of sub-constructs of personality traits.

\begin{tabular}{lccccc}
\hline & N & Minimum & Maximum & Mean & Std. Deviation \\
\hline Extraversion & 120 & 10 & 23 & 15.40 & 3.31 \\
Agreeableness & 120 & 6 & 20 & 14.11 & 3.06 \\
Openness to experience & 120 & 8 & 20 & 15.56 & 3.49 \\
Neuroticism & 120 & 7 & 20 & 13.38 & 3.11 \\
Conscientiousness & 120 & 7 & 20 & 14.67 & 2.76 \\
\hline
\end{tabular}

The possible range of score for all five sub-constructs of personality traits except extraversion is between 4 and 20 and for extraversion is between 5 and 25. As it can be seen in Table 2, Openness to Experience has the highest mean score (15.56) and Neuroticism has the
The descriptive analysis of data including mean $(\mathrm{M})$ and standard deviation (SD) for the variables under study are calculated and provided in Table 2 .

\section{Table 3}

Descriptive statistics of students' willingness to write.

\begin{tabular}{lccccc}
\hline & $\mathbf{N}$ & Minimum & Maximum & Mean & Std. Deviation \\
\hline Willingness to write & 120 & 66.00 & 158.00 & 119.40 & 18.25 \\
\hline
\end{tabular}

As it can be seen in Table 3, the minimum score for Willingness to Write is 66 and maximum score is 158 . Moreover, the mean score is 119.40 with standard deviation of 18.25 . lowest mean score (13.38). Table 3 presents descriptive statistics of students' willingness to write. The possible range of score for willingness to write with 38 items is between 38 and 190.
Table 4 presents descriptive statistics of students' writing score. The possible range of score for this test is between 0 and 9 . 
Table 4

Descriptive statistics of students' writing score.

\begin{tabular}{lccccc}
\hline & $\mathbf{N}$ & Minimum & Maximum & Mean & Std. Deviation \\
\hline Writing Score & 120 & 1 & 9 & 7.01 & 1.36 \\
\hline
\end{tabular}

As it can be seen in Table 4, the minimum score for Writing Score is 1 and maximum score is 9. Moreover, the mean score is 7.01 with standard deviation of 1.36 .
Table 5 shows the information obtained from Cronbach alpha analyses for willingness to write and personality types questionnaires.

\section{Reliability of the questionnaires}

Table 5

Results of Cronbach alpha indexes after reliability analysis.

\begin{tabular}{llcc}
\hline Scale & Subscales & Number of items & Cronbach alpha \\
\hline Willingness to write & $\ldots \ldots \ldots \ldots . .$. & 38 & .85 \\
\hline \multirow{5}{*}{ Personality traits } & Extraversion & 5 & .75 \\
& Agreeableness & 4 & .78 \\
& Conscientiousness & 4 & .93 \\
& Neuroticism & 4 & .84 \\
& Openness to Experience & 4 & .80 \\
\hline
\end{tabular}

As can be seen, the utilized questionnaires gained acceptable indexes of Cronbach alpha as a whole as well as in their subscales. Concerning inter-rater reliability, students' writing were scored by two professionals in the field and the reliability index reported was .84 .

\section{Results of research questions}

\section{Results of research question one}

\section{Table 6}

Results of Pearson Correlation between Iraqi EFL learners' willingness to write and their writing ability.

\begin{tabular}{llc}
\hline & & Writing ability \\
\hline Willingness to write & Pearson Correlation & .40 \\
& Sig. (2-tailed) & .00 \\
& $\mathrm{~N}$ & 120 \\
\hline
\end{tabular}

Major Research Question 1: Is there any significant relationship between Iraqi EFL learners' willingness to write and writing ability?

To assess the major research question 1, Pearson correlation was used. Table 6 shows the results of Pearson correlation between Iraqi EFL learners' willingness to write and their writing ability.
Results of Pearson correlation indicated that there is a positive moderate significant relationship between willingness to write and their writing ability $(r=.40$, $p<.05)$.

\section{Results of research question two}

Major Research Question 2: Is there any significant relationship between Iraqi EFL learners' personality type and writing ability?

\section{Minor research questions:}

Q 2a. Is there any significant relationship between Iraqi EFL learners' openness to experience and writing ability?
Q 2b. Is there any significant relationship between Iraqi EFL learners' agreeableness and writing ability? Q 2c. Is there any significant relationship between Iraqi EFL learners' extraversion and writing ability?

Q 2d. Is there any significant relationship between Iraqi EFL learners' conscientiousness and writing ability? $\mathrm{Q} 2$ 2. Is there any significant relationship between Iraqi EFL learners' neuroticism and writing ability?

To assess the major research question 2 as well as the minor questions, Pearson correlation were used. Table 7 shows the results of Pearson correlation between writing ability and sub-constructs of personality trait. 
Table 7

Results of Correlation between writing ability and subconstructs of personality trait.

\begin{tabular}{|c|c|c|c|c|c|}
\hline & Ex. & Ag. & Opp. & Neu. & Con. \\
\hline Writing Ability & $.20^{* *}$ & $.22^{* *}$ & $.51 * *$ & $-.15^{*}$ & $.55^{* *}$ \\
\hline
\end{tabular}

As it can be seen in Table 7, among five sub-factors of personality traits, conscientiousness has the highest positive correlation $(r=.55, p<.05)$ and Neuroticism has the lowest negative correlation $(r=-.15, p<.05)$ with writing ability. In addition, there are positive moderate significant relationships between openness to experience $(r=.51, p<.05)$, and weak positive relationship between agreeableness $(r=.22, p<.05)$, and extraversion $(r=.20, p<.05)$ with writing ability.

\section{Discussion}

From the results obtained, some key findings emerge including the fact that willingness to write and writing ability are moderately correlated and that from among five sub-factors of personality traits, conscientiousness has the highest positive correlation and Neuroticism has the lowest negative correlation with writing ability. From the results, it is clear that individuals with strong willingness to write are more likely to have better writing ability. Moreover, students with higher level of neuroticism have lower ability in writing since neuroticism is a trait which is characterized by stress, anxiety, individual instability and sadness. What is more, an important feature of conscientiousness is that it includes high levels of thoughtfulness, enjoyment, desire control, and goal-directed behaviors. Therefore, students with such a trait are mindful and organized about their writing skill and so they plan ahead and think about how to write well. Language learners with high levels of Conscientiousness enjoy better writing ability as the result of higher willingness to write. On the other hand, those language learners with high levels of Neuroticism, because of the negative correlation with willingness to write will suffer from low willingness to write and they are not expected to become good writers.

In addition, the findings hint that there are positive moderate significant relationships between openness to experience with writing ability. Openness to experience characterizes curiosity about the world, creativity, eagerness to learn new things and gratification of new experiences and imagination. Our results casts a new light on the fact that Iraqi EFL students who are high in this trait are somehow better writers than the ones who are low in openness to experience and have traditional thinking. Promoting EFL students' sense of openness to experience and creativity may lead to good results in writing ability.
It is worth discussing the interesting facts revealed by the results of the study including weak positive relationship between agreeableness and extraversion with writing ability. As agreeableness dimension includes empathy, trust, and kindness, EFL students with such personality type enjoy assisting their peers and are more cooperative rather than competitive in the classroom. The weak positive relationship between agreeableness and writing ability might be due to the dominant beliefs among Iraqi students who are probably not willing to cooperate with other students. Likewise, the results found evidence for the weak positive relationship between extraversion with writing ability. The extraverted students are sociable, assertive, risk taker, and easy-going while introverted students are reflective and unwilling to cooperate with others or join in activities. Extrovert students gain their knowledge through communication with others while its counterpart, introvert, enhance their knowledge through reflection and reading books. The weak positive correlation between extraversion and writing ability of Iraqi students can be due to fact that both characteristics of extrovert and introvert possess featurs than can pave the way for improving writing ability.

This result ties well with previous studies wherein Scovel [17] expressed that there might be high correlation between some personality traits and language proficiency. Also, Johnson [18] presented a meaningful correlation between the EFL students' conscientiousness and extraversion and their willingness to write as well as writing ability. In line with another study by Skeel [19] the interrelationship among personality types and willingness to write among EFL university students were studied. The researcher reported a significant relationship among the personality types especially openness to experience, agreeableness, and extraversion with willingness to write among the subjects of the study [19].

The results of the present study are also in accordance with the findings gained by Izadi [20] who focused on the relationship between Iraninan EFL learners' extroversion/introversion personality types and willingness to communicate in writing. The result of the study showed that extrovert personality type participants as significantly more successful in making a communicative connection in writing skill. This implies that extraversion and writing ability are interrelated. The extroverts seem to seek more communicative 
opportunities including writing to express themselves and they are better users of language opportunities. The result is also equal to the findings obtained by Duff [21] who worked particularly on personality dimension of extroversion with written performance. Duff concluded that the extravert participants are more active participation in the writing assessment task and that their written task have higher level of accuracy.

These results are more meticulous in finding the relationship between personality type and writing ability and go beyond previous general reports by ChamorrodPremuzic and Furnham [22] who found the overall relationship between personality types and different aspects of language learning skills and suggested that personality types have power to help us in predicting academic success and failure. In sum, different investigations showed the importance of writing and its relationship with personality type and willingness to write. key findings that emerge include the fact that willingness to write and writing ability are moderately correlated and that from among five sub-factors of personality traits, conscientiousness has the highest positive correlation and Neuroticism has the lowest negative correlation with writing ability. In addition, there are positive moderate significant relationships between openness to experience, and weak positive relationship between agreeableness, and extraversion with writing ability.

\section{Conclusion}

This study aimed to delve into the relationships among intermediate EFL Iraqi students' willingness to write, personality types including openness, conscientiousness, neuroticism and agreeability and writing ability. Learning a second language can never be complete without a good mastery of writing ability so investigating the factors contributing to writing ability is of crucial importance. Concerning the vitality of English writing all around the world, one comes to the idea that not only writing ability but also willingness to write should be enhanced due to the fast pace of development in science and technology. Moreover, according to Furnham [22], during the process of acquiring second language skills including writing, all learners are under the influence of their personality types. So far there have been a lot of different studies on the role of personality types and the ways they influence the individuals when trying to encode meaning in the acts of communication. This experiment adds to a growing corpus of research showing a positive significant relationship between two variables of willingness to write and writing ability among Iraqi EFL learners. The results also showed significant positive relationships among the four sub elements of personality types including extraversion, openness to experience, agreeableness, and conscientiousness and also a negative significant relationship between neuroticism and writing ability among Iraqi EFL learners. The broad implication of the present research for teachers is that personality types and the ways it may affect individuals willingness to write. For this reason, there should be workshops, the purpose of which is familiarizing novice teachers with different traits of each personality type so that teachers can better manage their classrooms by using the appropriate instructional behaviors. All teachers can play important roles in making appropriate learning environment in teaching classrooms. For example, teachers should decrease learners' anxiety as a basic feature of neuroticism.

Collectively, Teachers should be informed about psychological features which are considered as deterrent to learning and participation in classroom activities in university courses, workshops and TTC programs. However, our data suggest that we still have a long way to go to understanding the practical solutions to solve psychological factors inhibiting writing ability.

\section{References}

1. Alnufaie M, Grenfell M. EFL writing apprehension: The Macro or the Micro? J Art Humanit. 2013; 2: 79-89. 2. Demény P. Developing written text production competence using the reader-response method. Acta Didact Napocensia. 2012; 5: 53-60.

3. Ni'mah U. Case study: The role of learning strategies, personality and motivation in the second language acquisition: writing proficiency of a somalian student. J Eng Acad Specif Purp. 2020; 3: 43-55.

4. Maleki A, Zeraatpishe M, Faravani A. A path analysis of typical intellectual engagement, learning style and preference for assessment. Int J Instr. 2019; 12: 12391250.

5. Dörnyei $Z$. Individual differences in second language acquisition. AIL $A$ Rev. 2006; 19: 42-68.

6. Amirian Z, Karamifar Z, Youhanaee M. Structural equation modeling of EFL learners' willingness to communicate and their cognitive and personality traits. Appl Res Eng Lang. 2020; 9: 103-136.

7. Faravani A, Atai MR. Portfolio assessment and the enhancement of higher order thinking through multiple intelligence and dialogic feedback. Issu Lang Teach. 2015; 4: 21-25.

8. Faravani A, Atai MR. Multiple intelligences, dialogicbased portfolio assessment, and the enhancement of higher order thinking. J Teach Lang Ski. 2015; 33: 19-44. 9. Furnham A, Chamorro-Premuzic T, McDougall F. Personality, cognitive ability, and beliefs about intelligence as predictors of academic performance. Learn Indiv Differ. 2003; 14: 47-64.

10. Ehrman ME, Lou Leaver B, Oxford RL. A brief overview of individual differences in second language 
learning. Syst. 2003; 31: 313-330.

11. Elbow P. Writing with power: Techniques for mastering the writing process. Oxford University Press, 1998.

12. Klein PD, Boscolo P, Gelati C, Kirkpatrick LC. New directions in writing as a learning activity. Writ Learn Act Brill. 2014; 1-14.

13. Lefever R, Carati D. Intrinsic patterns in anisotropic multicomponent diffusive systems at equilibrium. Phys A Stat Mech Appl. 1995; 213: 90-104.

14. Khajavy GH, Ghonsooly B, Hosseini Fatemi A, Choi CW. Willingness to communicate in English: A microsystem model in the Iranian EFL classroom context. Tesol Q. 2016; 50: 154-180.

15. Khormaee F, Etemaad J. Investigating the psychometric adequacy of nostalgia inventory (NI). 2018.

16. Wang YH, Liao H-C. The application of learning portfolio assessment for students in the technological and vocational education system. Asian EFL J. 2008;
10: $132-154$.

17. Scovel T. The effect of affect on foreign language learning: A review of the anxiety research. Lang Learn. 1978; 28: 129-142.

18. Chamorro-Premuzic T. Personality and individual differences. John Wiley \& Sons, 2016.

19. Skeel RL, Neudecker J, Pilarski C, Pytlak K. The utility of personality variables and behaviorally-based measures in the prediction of risk-taking behavior. Pers Indiv Differ. 2007; 43: 203-214.

20. Izadi S, Salehi E, Gharebaghi MM. Evaluation of students satisfaction using EFQM model: A case study: Mazandaran University Students. Iran High Educ Assoc. 2007; 1: 27-58.

21. Duff A, Boyle E, Dunleavy K, Ferguson J. The relationship between personality, approach to learning and academic performance. Pers Indiv Differ. 2004; 36: 1907-1920.

22. Furnham A. Personality and learning style: A study of three instruments. Pers Indiv Differ. 1992; 13: 429-438.

\section{KURMANJ}

Copyright: (C) 2021 The Author(s); This is an open-access article distributed under the terms of the Creative Commons Attribution License (http://creativecommons.org/licenses/by/4.0), which permits unrestricted use, distribution, and reproduction in any medium, provided the original work is properly cited.

Citation: Sharrad A, Faravani A. Delving into the Relationships among Iraqi EFL Learners' Willingness to Write, Personality Types and Writing Ability. KURMANJ, 2021; 3(1): 23-29.

https://doi.org/10.47176/kurmanj.3.1.23 